\title{
Histopathological study of precursor and neoplastic lesions of endometrium in endometrial samplings
}

\author{
Nanda J. Patil, Heena P. Shah, Mamta Bharti* \\ Department of Pathology, Krishna Institute of Medical Sciences, Karad, Satara, Maharashtra, India
}

Received: 29 December 2016

Revised: 04 January 2017

Accepted: 30 January 2017

\author{
*Correspondence: \\ Dr. Mamta Bharti, \\ E-mail:dr.mamtabharti@gmail.com
}

Copyright: $\odot$ the author(s), publisher and licensee Medip Academy. This is an open-access article distributed under the terms of the Creative Commons Attribution Non-Commercial License, which permits unrestricted non-commercial use, distribution, and reproduction in any medium, provided the original work is properly cited.

\begin{abstract}
Background: Endometrial lesion presenting as abnormal uterine bleeding, abdominal pain and menstrual irregularities form most common presenting complaint in women of reproductive age group and in premenopausal women. Endometrial sampling is a safe and effective diagnostic step in evaluation of abnormal uterine bleeding (AUB). The present study was carried out to establish histopathological diagnosis of precursor and neoplastic lesions of endometrial samplings in correlation with clinical details and other investigations.

Methods: A two-year prospective study was carried out in the department of pathology in a tertiary care hospital from June 2013-May 2015 which included endometrial samplings of precursor and neoplastic lesions. All cases were analyzed histopathologically.

Results: The study included 46 cases comprising $30 \%$ of total 153 endometrial samplings. Out of these, precursor lesions were 36 cases $(23.6 \%)$ and malignant were 10 case $(5.8 \%)$. The highest incidence of precursor lesions (endometrial hyperplasia) was in the age group of 41- 50 years. Among the precursor lesions, endometrial hyperplasia without atypia (86\%) was the commonest observation followed by atypical hyperplasia (14\%).

Conclusions: For the correct evaluation of cases presenting with AUB, histopathological evaluation of endometrial samplings is the gold standard method.
\end{abstract}

Keywords: AUB, Endometrial hyperplasia, Neoplastic lesion, Precursor lesion

\section{INTRODUCTION}

Most of the endometrial lesions presenting as abnormal uterine bleeding, abdominal pain and menstrual irregularities in the perimenopausal age group are precursor and malignant lesions. Early diagnosis of these lesions helps in the definitive management and hence can prevent further morbidity and mortality related to them. Endometrial sampling is a safe and effective diagnostic step in evaluation of precursor and malignant lesions of the endometrium. ${ }^{1}$ The present study was carried out to establish histopathological diagnosis of precursors and neoplastic lesions of endometrial samplings in correlation with clinical details and other investigations.

\section{METHODS}

A two year prospective study was carried out in the department of pathology in a tertiary care hospital from June 2013-May 2015 which included 46 cases of endometrial samplings of precursors and neoplastic lesions. The specimens were received in $10 \%$ formalin. After overnight fixation the tissue was processed for routine tissue processing as per standard guidelines. 
Histopathological diagnosis was given in light of clinical details and radiological findings.

\section{RESULTS}

The study included 46 cases comprising $30 \%$ of total 153 endometrial samplings. Out of these, precursor lesions were 36 cases $(23.6 \%)$ of all endometrial samplings and malignant tumors were 10 cases $(5.8 \%)$. Patients presenting as abnormal uterine bleeding in the perimenopausal age group were evaluated on the basis of radiological and histopathological examination of endometrial samplings. The sensitivity and specificity of USG with histopathology was analyzed. The overall sensitivity of USG was $80 \%$ and specificity was $81 \%$.

\section{Precursor lesion}

Category included 36 cases out of which 31 cases were of endometrial hyperplasia without atypia (86\%) and 5 cases were of atypical hyperplasia (14\%).

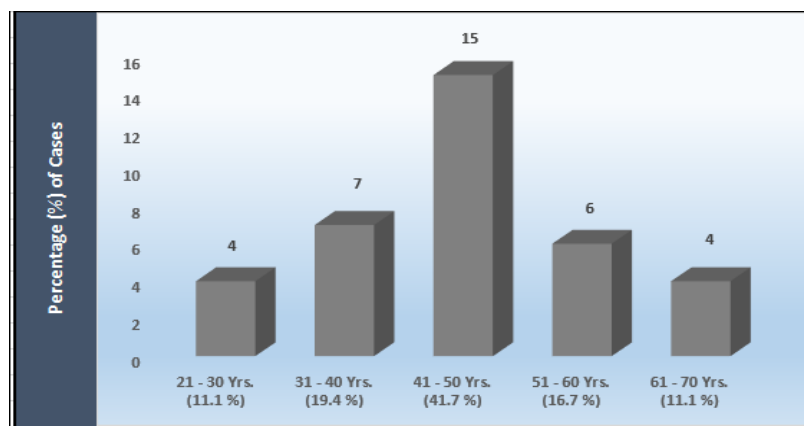

Figure 1: Age distribution of precursor lesions.

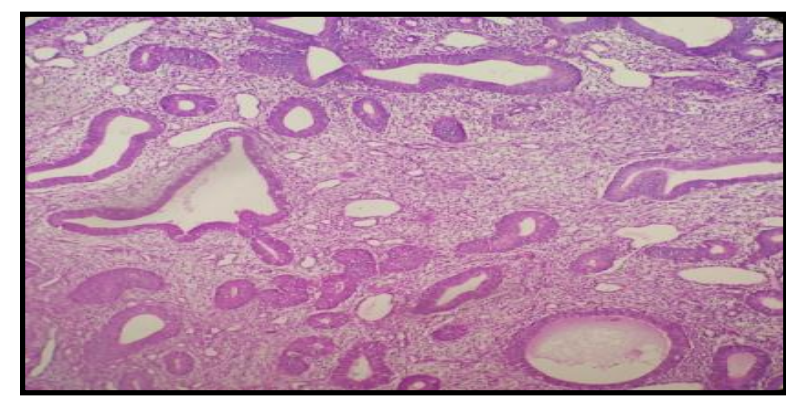

Figure 2: Endometrial hyperplasia without atypia showing back to back arrangement of glands with no cellular atypia $(H \& E$ 100x).

Maximum number of cases $(41.7 \%)$ were in age group of 41-50 years. 33 cases presented with abnormal uterine bleeding (AUB) and 3 patients presented with infertility. In more than $50 \%$ of cases hyperplasia was missed clinically. Malignant Lesions - Out of all endometrial samplings, 10 patients $(5.8 \%)$ revealed malignant lesions, $80 \%$ of which were in post-menopausal age group. All the cases presented with post-menopausal bleeding.

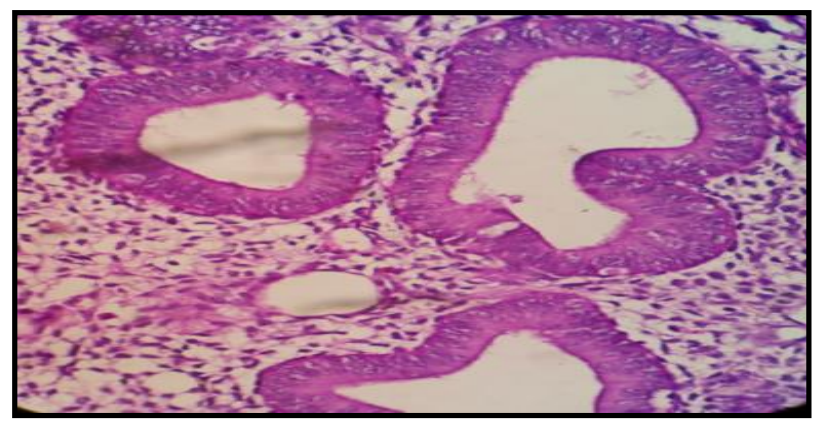

Figure 2: Endometrial hyperplasia without atypia with back to back arrangement of glands with stratification, increased mitosis \& no nuclear atypia (H\&E 400x).

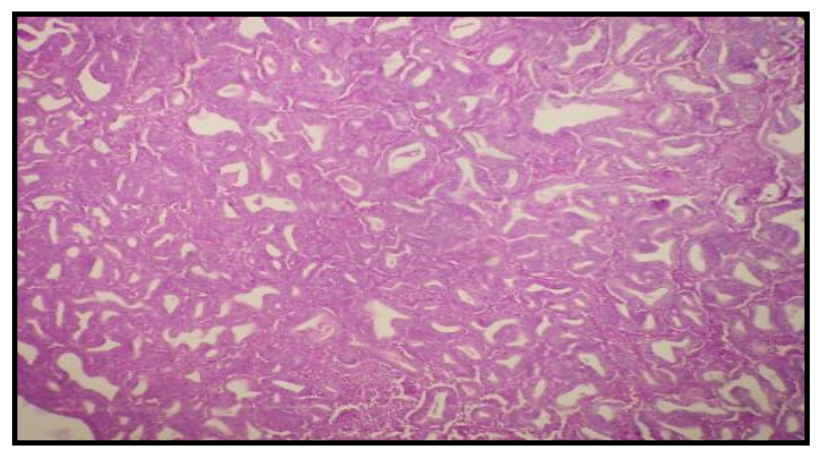

Figure 3 : Atypical hyperplasia showing back to back arrangement of glands with cellular atypia (H\&E 100x).

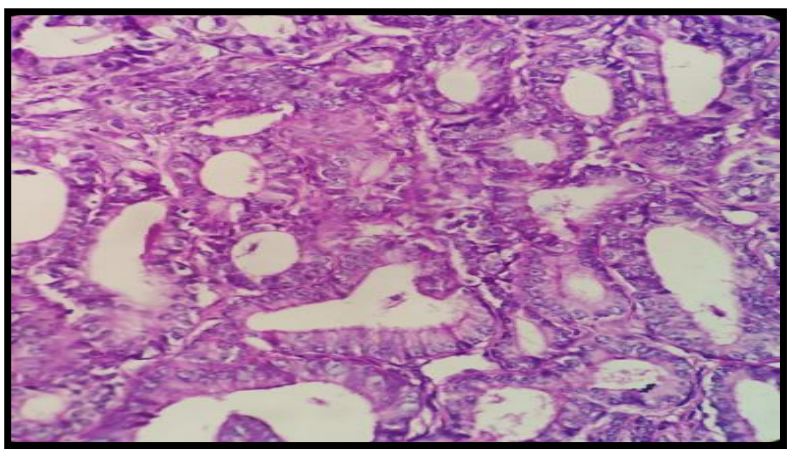

Figure 4: Atypical hyperplasia showing pseudo stratification in glands with nuclear atypia (H\&E 400x).

Table 1: Age distribution of malignant lesions.

\begin{tabular}{|l|l|l|}
\hline Age group & No. of cases & Percentage \\
\hline $41-50$ & 2 & 20 \\
\hline $51-60$ & 4 & 40 \\
\hline $61-70$ & 4 & 40 \\
\hline Total & 10 & 100 \\
\hline
\end{tabular}

Histopathological diagnosis - histopathological diagnosis given was endometrioid carcinoma-6 cases $(60 \%)$, carcinoma extending from cervix-3 cases (30\%), Carcinosarcoma-1 case $(10 \%)$. 


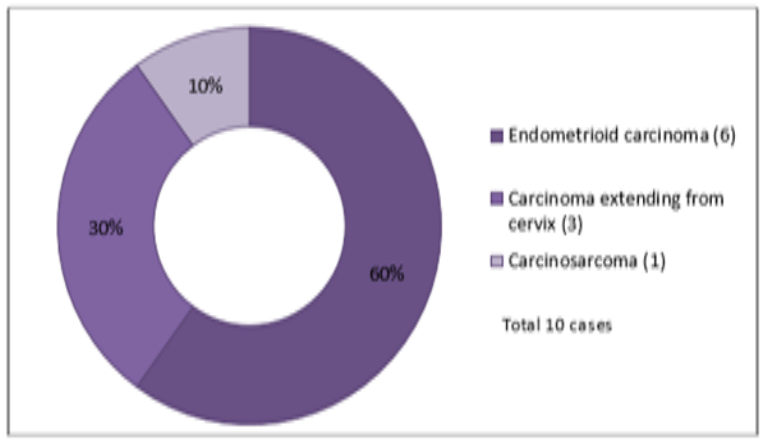

Figure 5: Histopathological diagnosis in different types of endometrial carcinomas.

Out of 6 cases of endometrioid carcinoma, 4 cases were well differentiated carcinoma while 2 cases were moderately differentiated carcinoma. There were 2 cases of squamous cell carcinoma of cervix and 1 case was villoglandular adenocarcinoma of cervix extending up to endometrium.

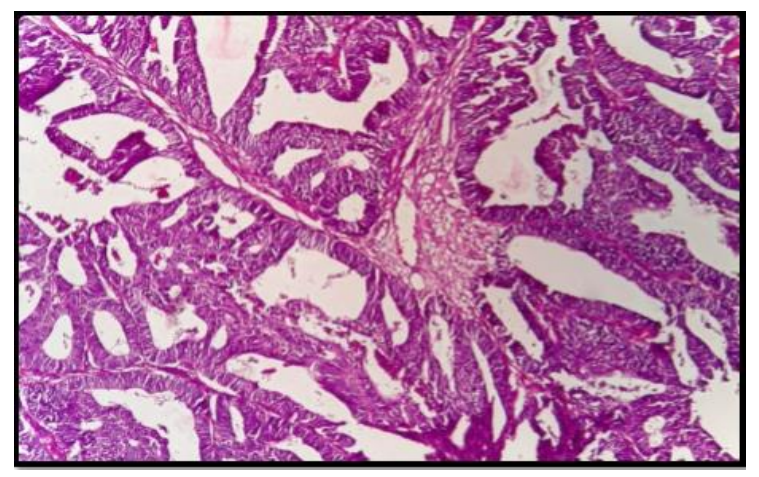

Figure 6: Endometrioid carcinoma showing neoplastic cells arranged in glandular pattern with minimal stroma (H\&E 100x).

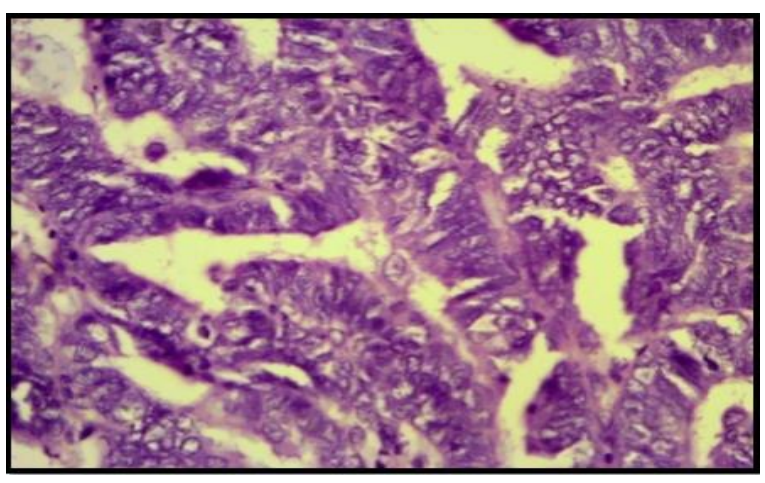

Figure 7: Endometrioid carcinoma showing glandular pattern with marked nuclear atypia (H\&E 400x).

\section{DISCUSSION}

The present study includes histopathological examination of precursor and neoplastic lesions of endometrium in endometrial samplings comprising of $30 \%$ of endometrial samplings. Precursor lesions were $23.6 \%$ of all endometrial sampling while $5.8 \%$ were malignant tumors and abnormal uterine bleeding (AUB) was the most common presentation in these cases. Precursor lesions i.e, endometrial hyperplasia formed the majority of cases (78.6\%), which also presented in the premenopausal age group (41.7\%).

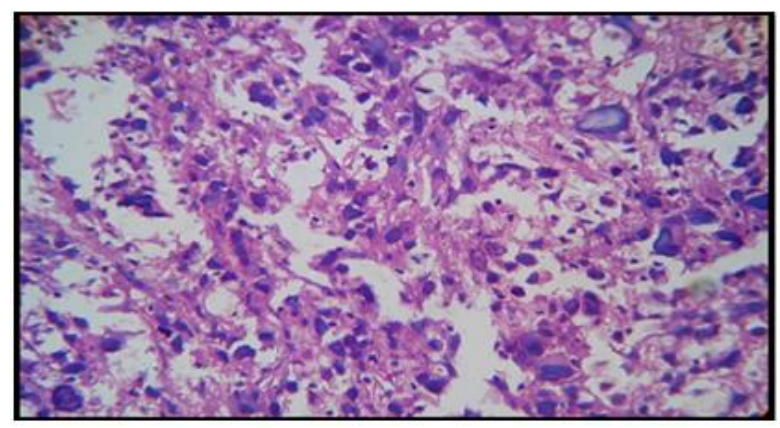

Figure 8: Carcinosarcoma-Sarcomatous component with marked pleomorphism and bizarre cells (H\&E 400x).

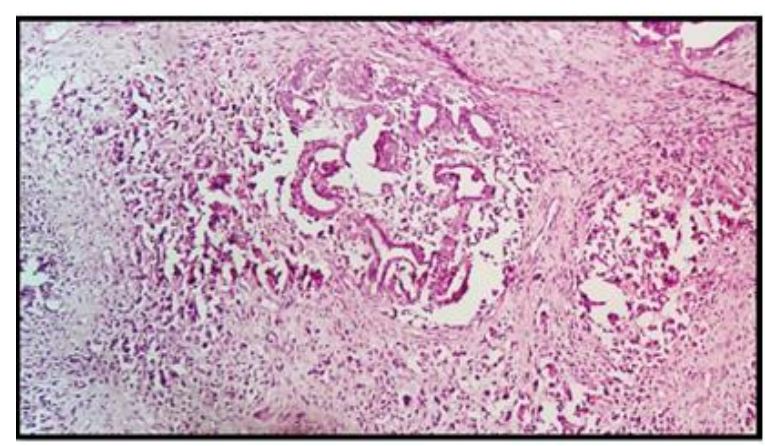

Figure 9: Carcinosarcoma showing malignant component of both glandular and stromal elements. (H\&E 100x).

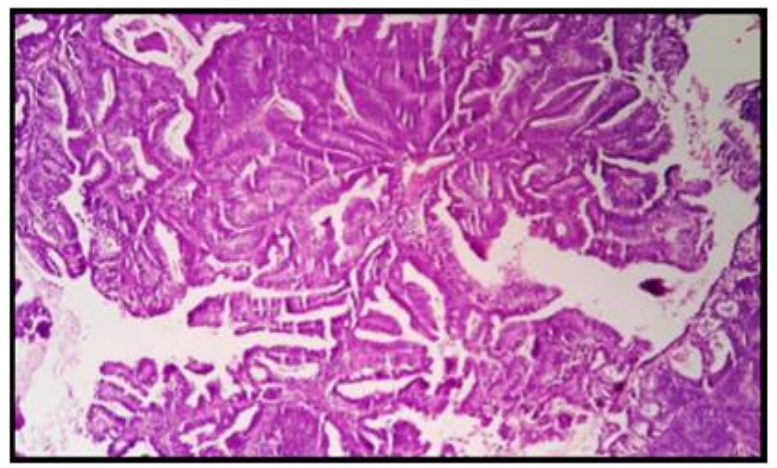

Figure 10: Villoglandular carcinoma showing arrangement of glands in villous and glandular configuration $(H \& E$ 100x).

The similar observation was revealed by various other studies. $^{2-6}$ Among the precursor lesions, endometrial hyperplasia without atypia (86\%) was the commonest observation followed by atypical hyperplasia (14\%). This was in concordance with other studies. ${ }^{7,8} 5.8 \%$ cases 
revealed malignant lesions, the clinical presentation in most of these cases was postmenopausal bleeding as revealed by other studies. ${ }^{3,5}$ The malignant lesions included endometrial carcinoma (60\%), carcinoma extending from cervix (30\%) and carcinosarcoma (10\%). Endometrial hyperplasia was missed clinically in more than $50 \%$ cases. However, ultrasonography was more useful in making the diagnosis of precursor and neoplastic lesions of endometrium and revealed sensitivity of $80 \%$ and specificity of $81 \%$.

\section{CONCLUSION}

Endometrial hyperplasia forms the majority of cases in the pre-menopausal age group and their clinical presentation is AUB. Identification of endometrial hyperplasia is important as it is a precursor of endometrial carcinoma. Patients presenting with postmenopausal bleeding should be investigated thoroughly to rule out malignancy. Clinical evaluation alone is not sufficient, clinical details along with radiological findings are essential for making precise diagnosis of endometrial pathology. For the correct evaluation of cases presenting with AUB, histopathological evaluation of endometrial samplings is the gold standard method. With recent diagnostic modalities endometrial biopsies still play an essential role in diagnosis of precursor and malignant lesions of endometrium.

Funding: No funding sources

Conflict of interest: None declared

Ethical approval: The study was approved by the Institutional Ethics Committee

\section{REFERENCES}

1. Lampe B, Kirzl R, Hantschmann P. Reliability of tumour typing of endometrial carcinoma in prehysterectomy curettage. Int J Gynecol Pathol. 1995;14:2-6.

2. Doraiswami S, Johnson T, Rao S, Rajkumar A, Vijayaraghavan K, Panicker VK. Study of endometrial pathology in abnormal uterine bleeding. J Obstet Gynecol India. 2011;61(4):426-30.

3. Jagdale A, Sharma A. Histopathological study of endometrium in abnormal uterine bleeding in relation to different age groups, parity and clinical symptomatology. Int $\mathbf{J} \mathbf{C l i n}$ and Biomed Res. 2015;1(2):90-95.

4. Dadhania B, Dhruva G, Agravat A, Pujara K. Histopathological study of endometrium in dysfunctional uterine bleeding. Int $\mathrm{J}$ Res Med. 2013;2(1):20-24.

5. Agarwal S, Mathur A, Vaishnav K. Histopathological study of endometrium in abnormal uterine bleeding in women of all age groups in western Rajasthan (400 cases). Int J Basic and Applied Med Sci. 2014;4(3):15-18.

6. Moghal N. Diagnostic value of endometrial curettage in abnormal uterine bleeding - a histopathological study. J Pak Med Assoc. 1997;47(12):2959.

7. Baral R, Pudasini S. Histopathological pattern of endometrial samples in abnormal uterine bleeding. $\mathrm{J}$ Path Nepal. 2011;1:13-6.

8. Abid M, Hashmi AA, Malik B, Haroon S, Faridi N, Edi MM, et al. Clinical pattern and spectrum of endometrial pathologies in patients with abnormal uterine bleeding in Pakistan: need to adopt a more conservative approach to treatment. BMC Women's Health. 2014;14:132.

Cite this article as: Patil NJ, Shah HP, Bharti M. Histopathological study of precursor and neoplastic lesions of endometrium in endometrial samplings. Int J Reprod Contracept Obstet Gynecol 2017;6:989-2. 